\title{
COVID-19 Course in Allergic Asthma Patients: A Spanish Cohort Analysis
}

\author{
Alicia Habernau Mena ${ }^{\text {'*, Ismael García-Moguel }}{ }^{2,3, *}$, María Vazquez de la Torre Gaspar ${ }^{4}$, Victoria Mugica ${ }^{5}$, \\ Maria Isabel Alvarado Izquierdo ${ }^{6}$, Maria Aranzazu Jimenez Blanco ${ }^{7}$, Mar Gandolfo-Cano ${ }^{8}$, Mar Jiménez Lara ${ }^{9}$, \\ Ana Gonzalez Moreno ${ }^{10}$, Pilar Saura Foix $\mathbb{D}^{11}$, Ana Navarro-Pulido ${ }^{12}$, Cristina Martin-Arriscado Arroba $\mathbb{D}^{13}$, \\ Julio Delgado Romero ${ }^{14}$, Javier Dominguez-Ortega ${ }^{15}$
On behalf of Asthma Committee of SOCIEDAD ESPAÑOLA DE ALERGOLOGÍA E INMUNOLOGÍA CLÍNICA (SEAIC)

\begin{abstract}
'Department of Allergy. Complejo Hospitalario de Mérida, Mérida, Spain; ${ }^{2}$ Department of Allergy, Hospital Universitario 12 de Octubre, Madrid, Spain; ${ }^{3}$ Instituto de Investigación Sanitaria Hospital 12 de Octubre (imas 12), Madrid, Spain; ${ }^{4}$ Department of Allergy, Hospital Universitario Infanta Leonor, Madrid, Spain; ${ }^{5}$ Department of Allergy, Hospital de la Princesa, Madrid, Spain; ${ }^{6}$ Department of Allergy, Hospital Universitario de Cáceres, Cáceres, Spain; ${ }^{7}$ Department of Allergy, Hospital Cruz Roja, Madrid, Spain; ${ }^{8}$ Department of Allergy, Hospital Universitario de Fuenlabrada, Madrid, Spain; ${ }^{9}$ Department of Allergy, Hospital de Toledo, Toledo, Spain; ${ }^{10}$ Department of Allergy, Fundación Hospital Alcorcón, Madrid, Spain;

1 'Department of Allergy, Consorci Sanitari de Terrassa, Terrassa, Spain; ${ }^{12}$ Allergology Clinical Management Unit (UGC), El Tomillar Hospital, Sevilla, Spain; ${ }^{13}$ Research and Science Support Unit, Instituto de investigación Biomédica del Hospital Universitario 12 de Octubre I+12, Madrid, Spain;

${ }^{14}$ Department of Allergy, Hospital Universitario Virgen Macarena, Sevilla, Spain; ${ }^{15}$ Department of Allergy, Hospital Universitario La Paz. Instituto de Investigación (idiPaz), Madrid, Spain
\end{abstract}

*These authors contributed equally to this work

Correspondence: Ismael García-Moguel, Department of Allergy, Hospital Universitario 12 de Octubre, Av de Córdoba s/n, Zip code 28005, Madrid, Spain, Tel +34-645852229, Email Ismaelgmoguel@gmail.com

Purpose: The acute respiratory syndrome coronavirus 2 (SARS-CoV-2) pandemic has had a high impact on patients with chronic diseases. In the literature, there are different perspectives on asthma as comorbidity or risk factor on COVID-19 severity.

Patients and Methods: The aim of this retrospective study across 13 allergy departments in Spain was to determine the severity of COVID-19 in asthmatic adults followed in allergy departments and its relationship with atopy, clinical and demographic characteristics, phenotypes and laboratory data. In addition, lung function test and asthma control test (ACT) before and after COVID-19 were analyzed. Data was obtained from electronic medical records from March 2020 to April 2021.

Results: Two hundred one asthmatic patients were diagnosed with COVID-19 infection by validated detection test. About $30 \%$ of the patients were admitted for bilateral pneumonia. Advanced age, elevated D-dimer, lower numbers of lymphocytes and eosinophils, heart diseases and hypertension were associated with severe COVID-19. Allergic and mixed allergic/eosinophilic phenotype and their biomarkers (total IgE, aeroallergens sensitizations, allergic rhinitis, and blood eosinophilia) were related to fewer hospital admissions. Poor control and lower forced expiratory volume in the first second ( $\left.\mathrm{FEV}_{1}\right)$ were related to worse prognosis of COVID-19.

Conclusion: Asthmatic patients with allergic and eosinophilic phenotype have a better evolution of COVID-19 and lower risk of admissions. Older patients, cardiovascular comorbidities, AERD and eosinopenia are related to severity COVID-19.

Keywords: COVID-19, allergic asthma, eosinophils, asthma phenotype, SARS-CoV-2

\section{Introduction}

The SARS-CoV-2 infection has become a global epidemic since December 2019. It is characterized by producing lung damage, acute respiratory distress syndrome, and multiple-organ failure. ${ }^{1}$ Although most patients have mild disease or remain asymptomatic, a group of patients, especially those with comorbidities, present severe diseases including fatal outcomes. $^{2}$ The cellular gateway of SARS-CoV-2 is the angiotensin-converting enzyme II (ACE2) and transmembrane 
peptidase serin 2 (TMPRSS2). The expression of ACE2 is decreased in children and in allergic patients. ${ }^{3}$ SARS-CoV-2 induces an innate immune response, the viral protein $\mathrm{S}$ generates an activation of pro-inflammatory cytokines and cells recruitment in damaged tissue. It is common to find lymphopenia and eosinopenia, especially in patients with severe disease.

Asthma is a respiratory disease characterized by chronic airway inflammation and a poor antiviral immune response due to decreased expression of interferon-beta and alpha. ${ }^{4}$ Under this thought, the SARS-CoV2 would induce asthma exacerbations. However, there is little data on asthma attacks in asthmatic patients infected by SARS-CoV-2. ${ }^{5}$ Most studies worldwide do not include asthma as comorbidity associated with the risk of severity of COVID-19 infection, although severe clinical features have been described in smokers, associated comorbidities, oral corticosteroid treatment, and geriatric patients. ${ }^{2-10}$ Ren et al detected in a multivariable analysis protective effect in patients with allergic rhinitis and asthma in those aged less than 65 years and a greater risk of severe SARS-CoV-2 infection in patients with nonallergic asthma compared to allergic eosinophilic asthma. ${ }^{10}$ It is interesting to know how asthma and the different phenotypes influence the COVID-19 course.

\section{Materials and Methods}

The aim of this retrospective study across 13 hospitals in Spain was to determine the severity of COVID-19 in asthmatic adults, attended in allergy departments, and to evaluate differences in severity by demographic characteristics, comorbidities, sensitizations to aeroallergens, asthma phenotype, asthma biomarkers (Total Ige and eosinophilia), and laboratory data at the onset of COVID-19. The severity of COVID-19 was defined by hospital admission (Group 2) or not (Group 1). We also try to assess the influence of treatment on the course of COVID-19, establishing different treatment groups; patients using only short-acting beta-agonists (SABA), patients using only inhaled corticosteroids (IC), patients using a CI associated with a long-acting beta-agonist (LABA), patients using combination with IC/LABA and associated an antileukotriene (ALT) patient who used IC/LABA and associated a long-acting antimuscarinic (LAMA) or who used the combination of IC/LABA/LAMA/ALT. Associations between patients who were corticosteroids-dependent and who used biological drugs were also analyzed. In addition, pulmonary function test and asthma control test (ACT) scores before and after COVID-19 were analyzed. The inclusion criteria were asthmatic patients with a diagnosis of asthma according to GEMA 5.1 and GINA and a SARS-CoV-2 infection detected by real-time polymerase chain reaction (RTPCR), antigenic or antibody test. ${ }^{11}$ The patient also had to have the ability to understand and to sign the informed consent.

The source of information was the medical records from March 2020 to April 2021 of the patients selected for the study, as well as the patients themselves through questionnaires completed during their usual appointments to the health centers and which will have coincided with the usual clinical practice. The clinical data collection process will be carried out from the clinical history, storing the clinical-care data related to the study in a computerized database specifically designed for this purpose. This database will not store personal data, as they are encoded in the data collection process from the medical record. Each patient will be coded according to a code generated by the numerical assignment to each center participating in the study and a consecutive patient number. In each hospital, an independent ethics committee center approved the final study protocol. Written consent written informed was obtained from all patients to review their medical records. This study was performed in accordance with the Declaration of Helsinki. After approval of the local ethics committee and informed consent signature, data were obtained from electronic medical records from March 2020 to April 2021.

To check the normality distribution, the Shapiro-Wilk test will be used. The qualitative variables will be expressed in absolute numbers (number of cases) and in relative frequencies (percentage). The comparison of the characteristics of the population with respect to the severity of COVID-19 was calculated using the ANOVA test or the non-parametric Kruskal-Wallis test, chi-square test $\left(\mathrm{X}^{2}\right)$ or Fisher's exact test, depending on the nature of variables. All analyses are performed using SAS $^{\circledR}$ version 9.4 statistical software, and a significance level of $5 \%$ is considered.

\section{Results}

Two hundred one asthmatic patients diagnosed with COVID-19 infection were included. Sixty of 201 patients (29.85\%) were admitted for bilateral pneumonia (group 2) and 5 patients (2.49\%) in the Intensive Care Unit (ICU). The main 
characteristics and comorbidities of the total population by severity groups and the statistical significance with the probability of hospitalization are summarized in Table 1. When COVID-19 was diagnosed, advanced age, elevated D-dimer, lower numbers of lymphocytes and eosinophils, heart disease, and hypertension were statistically associated with a higher risk for hospitalization. In contrast, more elevated lactate dehydrogenase (LDH) and C-reactive protein (CRP) are associated with mild infection (group 1). LDH was measured only in 76 patients, and one of the nonhospitalized patients had an LDH value of $3610 \mathrm{mg} / \mathrm{dl}$ for another disease non-COVID-19 related and may be cause bias in our results. Patients with allergic and mixed allergic/eosinophilic phenotype had fewer hospital admissions (T2 asthma). In the same way, higher baseline total $\mathrm{IgE}$, the presence of allergic rhinitis, and sensitization to aeroallergens, were associated with a lower number of admissions in asthmatic patients in our sample. There were non differences in severity of COVID-19 between seasonal vs perennial aeroallergens sensitizations ( $\mathrm{p}=0.7)$. In patients with Aspirin Exacerbated Respiratory Disease (AERD), admissions were more frequent. In AERD patients (25 patients), 13 (52\%) were admitted for bilateral pneumonia and 1 of them to ICU. Hyposmia $(\mathrm{p}=0.0016)$ and hypogeusia $(\mathrm{p}=0.0059)$ in COVID-19 patients were associated with lower admission to hospital. Although there were no significant differences in asthma control and lung function before and after COVID-19, hospitalized patients had poorer control by ACT and lower $\mathrm{FEV}_{1}$ before infection (Table 2).

Regarding asthma medications, most of the patients were on maintenance inhaled corticosteroids (189 patients-94\%) and only $15(7 \%)$ patients were on daily systemic corticosteroids. 3 patients (20\% of this group) corticosteroidsdependent patients were admitted for bilateral pneumonia, and 12 patients had mild COVID-19. Twelve patients were only undergoing SABA treatment, of which $2(16.67 \%)$ were admitted, without statistically significant differences with the rest of the groups. No groups including biological drugs and systemic corticosteroid-dependent patients showed a statistical association with a lower possibility of developing severe infection ( $\mathrm{p}=0.566$ and $\mathrm{p}=0.3795$, respectively). In addition, we analyzed patients ALT users (106 patients, 52.7\%)-vs not and patients LAMA users (57 patients, 28.36\%) vs not with no differences founded in terms of the severity of COVID-19 $(\mathrm{p}=0.7954$ and $\mathrm{p}=0.3121)$.

\section{Discussion}

Some authors have proposed a certain protective role of some asthma phenotypes in COVID-19, mainly due to the T2immune response or to the treatment of asthma or both causes. ${ }^{5,6,8,9,12}$ The anti-inflammatory role of some T2 cytokines is well known; IL-4 and IL-13 inhibit the secretion of Th1 cytokines (IL-6, IL-1, TNF-alpha, and IL-12), in addition, IL4 suppresses the activation of Th1 cells from LTh0. This suggests that immunomodulation due to T2 inflammation can occur, which counteracts the inflammatory response of COVID-19., ${ }^{3,5,6,8,9}$ On the other hand, the entry of the virus into the host cell could be decreased in allergic rhinitis and asthma due to the decrease in ACE expression in these patients. ${ }^{3}$ Also, eosinophils play a fundamental role in airway T2 inflammation and have an antiviral protective ability, increasing virus clearance. A recent study included 951 patients evaluated in the emergency room for COVID-19 finding that those with previous blood counts of $\geq 150$ eosinophils $/ \mu \mathrm{L}$ were less likely to be hospitalized and less risk of mortality. ${ }^{12}$ In our series, the allergic and mixed eosinophilic-allergic phenotype and the main clinical characteristics and biomarkers of allergic phenotype as high total IgE, higher eosinophils levels, and sensitizations to aeroallergens, were associated with a lower risk of hospitalization, that we can explain with the immunoregulatory effect of $\mathrm{T} 2$ inflammation. Consequently, our study reinforces the hypothesis about the protector factor of allergic asthma in SARS-CoV-2 infection. ${ }^{13,14}$ In contrast, other studies have associated asthma with a more severe course, for example, Yang et al evaluated 219,959 patients who were tested for COVID-19, observing that patients with allergic rhinitis and asthma had a higher risk of positivity in the test and a more serious course of the disease. ${ }^{15}$ In another similar study with 17,278,392 patients tested for COVID-19 $(2,746,073)$ were asthmatics, they observed that only the risk of mortality associated with COVID-19 was increased in asthmatics who had recently received systemic corticosteroids. ${ }^{16}$ In these studies, we do not have data on asthma phenotypes or whether these patients were correctly diagnosed and followed up in specialized clinics. Moreover, higher levels of COVID-19 severity markers (D-dimer and PCR), lymphopenia and eosinopenia, were associated with high risk of hospitalized, and patients with AERD had more hospitalizations, possibly related to poorer asthma control and lung function in these patients. ${ }^{17}$ White et al analyzed a series of 19 patients with COVID-19 with a history of AERD. Two of 19 patients required hospitalization, one of them suffered a pulmonary thromboembolism. Most of these 
Table I Demographic Data, Comorbidities, Clinical Characteristics, Asthma Biomarkers, and Laboratory Data During COVID-19 Infection in Total Population of the Study and Severity Groups

\begin{tabular}{|c|c|c|c|c|c|}
\hline & $\begin{array}{l}\text { Total Population } \\
\qquad \mathbf{n = 2 0 I}\end{array}$ & $\begin{array}{l}\text { Group I: } N=|4| \\
\quad(70.15 \%)\end{array}$ & $\begin{array}{c}\text { Group 2: } N=60 \\
(29.85 \%)\end{array}$ & N Missed & $p$ value \\
\hline Age & $49.11(14.18)$ & $46.03(13.6 \%)$ & $56.35(12.9 \%)$ & 0 & $<0.001$ \\
\hline Body mass index $\mathrm{kg} / \mathrm{m}^{2}$ ) & $27.30(5.61)$ & 27.30 (5.99\%) & $27.29(4.58 \%)$ & 4 & 0.6276 \\
\hline Sex (Female) & 125 (62.19\%) & $86(60.99 \%)$ & 39 (65\%) & 0 & 0.5919 \\
\hline Race & & & & & 0.5227 \\
\hline Caucasian & $172(85.57 \%)$ & $122(86.52)$ & 50 (83.33\%) & 0 & \\
\hline Black & $2(1 \%)$ & $2(1.42 \%)$ & - & 0 & \\
\hline Arabic & I $(0.5 \%)$ & I (0.7I\%) & - & 0 & \\
\hline Hispanic & 26 (12.94\%) & $16(11.35 \%)$ & $10(16.67 \%)$ & 0 & \\
\hline Asthma early onset & 49 (24.5\%) & $40(28,57 \%)$ & 9 (15\%) & 0 & 0.4049 \\
\hline GERD & 66 (32.84\%) & 47 (33.3\%) & 19 (31.67\%) & 0 & 0.8179 \\
\hline $\mathbf{A H}$ & $36(17.91 \%)$ & 19 (13.48\%) & 17 (28.33\%) & 0 & 0.0119 \\
\hline Diabetes & II (5.4\%) & $6(4.26 \%)$ & $5(8.33 \%)$ & 0 & 0.2447 \\
\hline AERD & 25 (12.44\%) & 12 (8.5I\%) & $13(21.67 \%)$ & 0 & 0.0097 \\
\hline Asthma/COPD & 7 (3.48\%) & $3(2.13 \%)$ & $4(6.67 \%)$ & 0 & 0.1082 \\
\hline Cardiovascular diseases & 14 (6.96\%) & $5(3.55 \%)$ & $9(15 \%)$ & 0 & 0.0035 \\
\hline Allergic rinitis & 179 (89.05\%) & $130(92.2 \%)$ & 49 (8I.67\%) & 0 & 0.0286 \\
\hline Nasal polyps & $33(16.4 \%)$ & $22(15.6 \%)$ & $\mathrm{II}(\mathrm{I} 8.33 \%)$ & 0 & 0.6325 \\
\hline Atopic dermatitis & $26(12.94 \%)$ & $2 \mathrm{I}(14.8 \mathrm{I} \%)$ & $5(8.33 \%)$ & 0 & 0.2047 \\
\hline Positive prick test dust mites & $56(27.86 \%)$ & $40(28.37 \%)$ & $16(26.67 \%)$ & 0 & 0.0083 \\
\hline Positive prick test to pollen & I 54 (76.62\%) & II 4 (80.85\%) & $40(66.67 \%)$ & 0 & 0.0030 \\
\hline Positive prick test to fungi & 31 (15.42\%) & 27 (19.15\%) & $4(6.67 \%)$ & 0 & 0.0010 \\
\hline Positive prick test to dander & 91 (45.27\%) & $65(46.10 \%)$ & $26(43.33 \%)$ & 0 & 0.0083 \\
\hline $\begin{array}{l}\text { Allergic or allergic }+ \text { eosinophilic } \\
\text { phenotype }\end{array}$ & $174(88.37 \%)$ & $128(63.12 \%)$ & $46(22.88 \%)$ & 0 & 0.0073 \\
\hline $\begin{array}{l}\text { Baseline Eosinophils }\left(\text { cell } / \mathrm{mm}^{3}\right) \text { mean } \\
\text { (SD) }\end{array}$ & $331.69(246.91)$ & $332,24(250.08)$ & $330.35(241.18)$ & 5 & 0.8698 \\
\hline Total IgE (KU/L)) mean (SD) & $452.10(1352.33)$ & $522.14(1574.43)$ & $276.98(4 \mid 9.68)$ & 12 & 0.0188 \\
\hline $\begin{array}{l}\text { D-dimer COVID-19 (ng/mL) mean } \\
\text { (SD) }\end{array}$ & $1216.93(576 \mid .13)$ & $350.5(164.57)$ & I700.5 (7|74.50) & 134 & 0.0486 \\
\hline LDH COVID-I9(U/L) mean (SD) & $319.88(421.11)$ & $323.52(636.02)$ & $317.53(191.70)$ & 127 & 0.0003 \\
\hline $\begin{array}{l}\text { Neutrophils COVID-I } 9 \text { (cell/mm³) } \\
\text { mean (SD) }\end{array}$ & $5132.34(2942.52)$ & $4384.52(1908.6)$ & $5736.35(3469.67)$ & 107 & 0.0697 \\
\hline CRP COVID-I 9 (mg/d)) mean (SD) & $5.430(22.429)$ & $6.191(31.312)$ & $4.932(14.260)$ & 115 & 0.0079 \\
\hline
\end{tabular}


Table I (Continued).

\begin{tabular}{|c|c|c|c|c|c|}
\hline & $\begin{array}{l}\text { Total Population } \\
\qquad \mathbf{n = 2 0 \text { I }}\end{array}$ & $\begin{array}{l}\text { Group I: } N=|4| \\
\quad(70.15 \%)\end{array}$ & $\begin{array}{c}\text { Group 2: } N=60 \\
(29.85 \%)\end{array}$ & N Missed & $p$ value \\
\hline $\begin{array}{l}\text { Lymphocytes COVID-19 (cell/mm³) } \\
\text { mean (SD) }\end{array}$ & I 357.65 (824.42) & I724,78 (930.4I) & $1068.46(594.73)$ & 108 & $<0.0001$ \\
\hline $\begin{array}{l}\text { COVID-19 Eosinophils }\left(\text { cell } / \mathrm{mm}^{3} \text { ) }\right. \\
\text { mean (SD) }\end{array}$ & 77.06 (100.89) & $123.78(|2| .27)$ & $41.04(62.3)$ & 116 & 0.0002 \\
\hline
\end{tabular}

Notes: Group I: non-hospitalized patients; Group 2: hospitalized patients. Bold font: $\mathrm{p}$ value statistically significant.

Abbreviations: GERD, gastroesophageal reflux disease; AH, arterial hypertension; COPD, chronic obstructive pulmonary disease; LDH, lactate dehydrogenase; CRP, $C$ reactive protein.

Table 2 Lung Function Before and After COVID in Total Population and in Group I (Patients Who Not Required Hospital Admission for COVID-19) and Group 2 (Hospitalized COVID-19 Patients)

\begin{tabular}{|c|c|c|c|c|c|c|c|}
\hline & $\begin{array}{l}\text { Total Population } \\
\qquad \mathbf{N}=20 \text { I }\end{array}$ & N Missed & $\begin{array}{c}\text { Group I: } N=|4| \\
(70.15 \%)\end{array}$ & N Missed & $\begin{array}{c}\text { Group 2: } N=60 \\
(29.85 \%)\end{array}$ & N Missed & $p$ value \\
\hline $\mathrm{FVC}(\mathrm{mL})$ mean $(\mathrm{SD})$ & $3363.46(909.91)$ & 15 & 3423.01 (919.12) & 11 & $3225.22(879.90)$ & 4 & 0.1322 \\
\hline $\mathrm{FVC}(\mathrm{mL}) \mathrm{p}$ mean $(\mathrm{SD})$ & 3365 (892.85) & 58 & $3478.83(9 \mid 2.45)$ & 43 & 3117.11 (803.48) & 15 & 0.9209 \\
\hline FVC (\%) mean (SD) & $97.50(17.16)$ & 12 & 98.45 (I7.7I) & 9 & $95.30(15.74)$ & 3 & 0.2778 \\
\hline FVC (\%) p mean (SD) & $103.98(83.80)$ & 59 & $98.50(22.12)$ & 42 & $116.61(49)$ & 17 & 0.8867 \\
\hline $\mathrm{FEV}_{\mathrm{I}}(\mathrm{mL})$ mean $(\mathrm{SD})$ & 2496.21 (896.67) & 14 & 2588.II (892) & 10 & $2281.23(878.19)$ & 4 & 0.0091 \\
\hline $\mathrm{FEV}_{\mathrm{I}}(\mathrm{mL}) \mathrm{p}$ mean $(\mathrm{SD})$ & 2554.56 (738.38) & 58 & $2685.64(802.60)$ & 42 & $2269.09(662.44)$ & 15 & 0.8867 \\
\hline $\mathrm{FEV}_{\mathrm{I}}(\%)$ mean $(\mathrm{SD})$ & 89.17 (22.66) & 11 & $90.40(23.06)$ & 8 & $86.28(21.62)$ & 13 & 0.2042 \\
\hline $\mathrm{FEV}_{1}(\%)$ p mean $(\mathrm{SD})$ & $94.66(33.808$ & 58 & $92.54(20.24)$ & 43 & $89.29(22.06)$ & 16 & 0.9318 \\
\hline ACT mean (SD) & $20.87(4.37)$ & 68 & $21.37(4.01)$ & 43 & $19.49(5.06)$ & 25 & 0.0289 \\
\hline ACTp mean (SD) & 20.42 & 32 & $20.70(4.33)$ & 17 & $19.64(4.01)$ & 15 & 0.9264 \\
\hline
\end{tabular}

Note: $\mathrm{P}$ values in bold font are statistically significant.

Abbreviations: FVC, baseline forced vital capacity; FEV , baseline forced expiratory volume in I second; ACT, baseline asthma control test; FVCP, post-COVID-I9 forced vital capacity; FEV, IP, post-COVID-19 forced expiratory volume in I second; ACTp, post-COVID-19 asthma control test.

patients were being treated with biologics for severe asthma and the authors consider that their cohort is very small and dependent on many other variables to draw specific conclusions. These authors affirm the current follow-up of 1000 patients with AERD where it does not seem that COVID-19 has greater morbidity than in the general population. As previously described, cardiovascular comorbidities and age are associated with more hospital admission and the presence of hyposmia and hypogeusia are associated with mild infection. ${ }^{2}$

Baseline poor asthma control and poor lung function were related with severity of COVID-19 in our series, but there wasn't changes in the asthma control and lung function before and after COVID-19. Our results also indicate a maintenance of control of asthmatic symptoms in the patients of our population measured by ACT and lung function test. Díaz-Campos et al report no difference in lung function but better ACT after COVID-19 due probably to better adherence to treatment and protection measures. ${ }^{18}$

An increase of $14.5 \%$ in asthma treatment adherence has been observed from January to March 2020 in one study, justified by the authors due to the COVID-19 pandemic but similar to those previously seen in fall where there are also more viral respiratory infections. ${ }^{19}$

In our series, we have also evaluated the possible influence of the treatments used for asthma in the hospitalizations of patients for COVID-19 without determining any statistically significant association. Several studies have tried to show 
that some treatments can influence the course of COVID-19. The first drugs to be evaluated have been inhaled corticosteroids. In vitro models have shown a decrease in virus replication with ciclesonide and budesonide in combination with glycopyrronium and formoterol. ${ }^{20,21}$ The other most studied asthma drugs for their possible influence on covid-19 have been biological drugs. And it is not something new, omalizumab years ago demonstrated its ability to increase the INF-alpha response in response to different respiratory viruses such as rhinoviruses. ${ }^{22}$ A study in children treated with omalizumab also reported a decrease in rhinovirus infections compared to the general population. ${ }^{23}$ Since the beginning of the pandemic, patients treated with biologics for severe asthma and the severity of COVID-19 have been reported. But only three big case series have been reported. ${ }^{18,24-26}$ The largest case series is the German series of 634 patients treated with biologics for severe asthma where 9 patients (1.4\%) were diagnosed with COVID-19 and more than half (5 patients) required admission to the ICU with intubation. ${ }^{25}$ These data do not correspond to a worse course of the disease in patients with severe asthma being treated with biologics. In another study during the first wave of COVID-19 in Spain, which evaluated 545 treated with biologics of which 35 were diagnosed with COVID-19, 8 of them required admission and 1 admission to the ICU, determining that these patients had no higher risk of contracting the infection or a greater severity. ${ }^{26}$

The main weakness of this study is that it is retrospective, and we do not have data from previous adherence to treatment of all patients. Furthermore, the presence of comorbidities in these patients may be a bias evaluate separately the influence of asthma in the course of COVID-19. For example, in our series, LDH is higher and statistically significant in non-hospitalized, contrary to all previous studies of biomarkers of poor evolution of COVID-19. ${ }^{27}$ It is likely to an extreme value of one patient $(3610 \mathrm{mg} / \mathrm{dl})$ for other disease and the low number of patients with this data.

\section{Conclusion}

The presence of allergic and eosinophilic phenotype and their characteristics (allergic rhinitis, pneumoallergens sensitizations, high total IgE and blood eosinophilia) have a better evolution in the course SARS-CoV-2 infection inside asthmatic cohort. Our study reinforces the hypothesis about the protector factor of eosinophils and T2 cytokines in COVID-19. Our study also shows that severe disease with poorer lung function and poor control, old age and cardiovascular comorbidities are associated with a more severe course of COVID-19. For this reason, we must educate our patients in the knowledge of the disease, the therapeutic adherence and optimize the treatment to avoid deterioration of lung function and poorer asthma control. More studies of long series of patients should be carried out to assess which phenotypes and endotypes (such as AERD) have a higher risk of suffering from severe COVID-19.

\section{Acknowledgments}

We thank the Asthma committee members of SEAIC and collaborators who participated in the study: Lys Herráez Herrera, Beatriz Torres Pérez, Alicia Enríquez Matas, Ruth Mielgo Ballesteros, Consuelo Fernández Rodriguez, Celine Galleani, Beatriz Moya, Juan Alberto Luna Porta, Pilar Barranco Sanz and Magdalena Lluch Bernal.

\section{Funding}

This research received no specific grant from any funding agency in the public, commercial, or not-for-profit sectors.

\section{Disclosure}

Dr García-Moguel was a consultant, speaker, and researcher promoted by GlaxoSmithKline, Sanofi Genzyme, AstraZeneca, Teva Pharmaceuticals, Mundipharma, Chiesi Novartis, and Stallergenes. Dra A Habernau was a consultant, speaker or researcher promoted by GSK, Sanofi Genzyme, AstraZeneca, Novartis and ALK-Abelló. Dr Julio Delgado Romero was a consultant for Bial and Sanofi, received speaker's honoraria from AstraZeneca, Bial, Chiesi, GlaxoSmithKline, Novartis, Sanofi and TEVA, received Grant/Research Support from AstraZeneca and Orion and received help assistance to meeting travel from Sanofi. Dr Javier Dominguez-Ortega was a consultant, speaker, and researcher promoted by Teva, Sanofi. Gsk, AstraZeneca, Chiesi, Bial and Novartis.

The authors report no other conflicts of interest in this work. 


\section{References}

1. Huang C, Wang Y, Li X, et al. Clinical features of patients infected with 2019 novel coronavirus in Wuhan, China. Lancet. 2020;395:497-506. doi:10.1016/S0140-6736(20)30183-5

2. Zhou F, Yu T, Du R, et al. Clinical course and risk factors for mortality of adult inpatients with COVID-19 in Wuhan, China: a retrospective cohort study. Lancet. 2020;395:1054-1062. doi:10.1016/S0140-6736(20)30566-3

3. Jackson DJ, Busse WW, Bacharier LB, et al. Association of respiratory allergy, asthma, and expression of the SARS-CoV-2 receptor ACE2 [published online ahead of print, 2020 Apr 22]. J Allergy Clin Immunol. 2020;S0091-6749(20):30551.

4. Zhu J, Message SD, Mallia P, et al. Bronchial mucosal IFN- $\alpha / \beta$ and pattern recognition receptor expression in patients with experimental rhinovirus-induced asthma exacerbations. J Allergy Clin Immunol. 2019;143(1):114-125.e4. doi:10.1016/j.jaci.2018.04.003

5. Wang JY, Pawanker R, Tsai HG, et al. COVID-19 and asthma, the good or the bad? Allergy. 2020. doi:10.1111//all.14480

6. Liu S, Zhi Y, Ying S. COVID-19 and asthma: reflection during the pandemic. Clin Rev Allergy Immunol. 2020;59(1):78-88. doi:10.1007/s12016020-08797-3

7. Halpin DMG, Farner R, Sibila O, et al. Do chronic respiratory disease or their treatment affect the risk of SARS-CoV-2 infection? Lancet Respir Med. 2020;8:436-438. doi:10.1016/S2213-2600(20)30167-3

8. Zhao Q, Meng M, Kumar R, et al. The impact of COPD and smoking history on the severity of Covid-19: a systemic review and meta-analysis. J Med Virol. 2020;25889:1915-1921.

9. Zhu Z, Hasegawa K, Ma B, Fujiogi M, Camargo CA Jr, Liang L. Association of asthma and its genetic predisposition with the risk of severe COVID-19. J Allergy Clin Immunol. 2020;146:327-329. doi:10.1016/j.jaci.2020.06.001

10. Ren J, Pang W, Luo Y, Cheng D, Qiu K, Rao Y. Impact of allergic Rhinitis and asthma on COVID-19 infection, hospitalization, and mortality. J Allergy Clin Immunol Pract. 2021; 10(1):124-133.

11. Guía española para el manejo del asma 5.0. Available from: www.gemasma.com. Accessed February 9, 2022.

12. Izquierdo JL, Almonacid C, González Y, et al. The impact of COVID-19 on patients with asthma. Eur Respir J. 2021;57:2003142. doi:10.1183/ $13993003.03142-2020$

13. Ferastraoaru D, Hudes G, Jershow E, Jariwala S, Karagic M, de Vos G. Eosinophilia in asthma patients is protective against severe COVID-19 illness. J Allergy Clin Immunol Pract. 9:1152-1162.

14. Wakabyashi M, Pawankar R, Narazaki H, Uede T, Itabashi T. Coronavirus disease 2019 and asthma, allergic rhinitis: molecular mechanisms and host-environmental interactions. Curr Opin Allergy Clin Immunol. 2021;21(1-7):1152-1163.

15. Yang JM, Koh HY, Moon SY, et al. Allergic disorders and susceptibility to and severity of COVID-19: a nationwide cohort study. $J$ Allergy Clin Immunol. 2020;146(4):790-798. doi:10.1016/j.jaci.2020.08.008

16. Williamson EJ, Walker AJ, Bhaskaran K, et al. Factors associated with COVID-19-related death using OpenSAFELY. Nature. 2020;584 (7821):430-436. doi:10.1038/s41586-020-2521-4

17. Iwalski ML, Agache I, Bavbek S, et al. Diagnosis and management of NSAID-exacerbated respiratory disease (N-ERD) - a EAACI position paper. Allergy. 2019;74:28-39. doi:10.1111/all.13599

18. Díaz-Campos RM, García-Moguel I, Pina-Maiquez I, Fernández-Rodríguez C, Melero-Moreno C. Prevalence and influence of COVID-19 in asthma control and lung function in severe asthma patients receiving biological treatment. J Investig Allergol Clin Immunol. 2021;31(4):362-363. doi:10.18176/jiaci.0695

19. Kaye L, Theye B, Smeenk I, Gondalia R, Barrett MA, Stempel DA. Changes in medication adherence among patients with asthma and COPD during the COVID-19 pandemic. J Allergy Clin Immunol Pract. 2020;8(7):2384-2385. doi:10.1016/j.jaip.2020.04.053

20. Yamaya M, Nishimura H, Deng X, et al. Inhibitory effects of glycopyrronium, formoterol, and budesonide on coronavirus HCoV-229E replication and cytokine production by primary cultures of human nasal and tracheal epithelial cells. Respir Investig. 2020;58(3):155-168. doi:10.1016/j. resinv.2019.12.005

21. Iwabuchi K, Yoshie K, Kurakami Y, Takahashi K, Kato Y, Morishima T. Therapeutic potential of ciclesonide inhalation for COVID-19 pneumonia: report of three cases. J Infect Chemother. 2020;26(6):625-632. doi:10.1016/j.jiac.2020.04.007

22. Gill MA, Liu AH, Calatroni A, et al. Enhanced plasmacytoid dendritic cell antiviral responses after omalizumab. J Allergy Clin Immunol. 2018;141 (5):1735-1743.e9. doi:10.1016/j.jaci.2017.07.035

23. Esquivel A, Busse WW, Calatroni A, et al. Effects of omalizumab on rhinovirus infections, illnesses, and exacerbations of asthma. Am J Respir Crit Care Med. 2017;196(8):985-992. doi:10.1164/rccm.201701-0120OC

24. García-Moguel I, Díaz Campos R, Alonso Charterina S, Fernández Rodríguez C, Fernández Crespo J. COVID-19, severe asthma, and biologics. Ann Allergy Asthma Immunol. 2020;125(3):357-359.e1. doi:10.1016/j.anai.2020.06.012

25. Eger K, Hashimoto S, Braunstahl GJ, et al. Poor outcome of SARS-CoV-2 infection in patients with severe asthma on biologic therapy. Respir Med. 2020;177:106287. doi:10.1016/j.rmed.2020.106287

26. Rial MJ, Valverde M, Del Pozo V, et al. Clinical characteristics in 545 patients with severe asthma on biological treatment during the COVID-19 outbreak. J Allergy Clin Immunol Pract. 2021;9(1):487-489.e1. doi:10.1016/j.jaip.2020.09.050

27. Martha JW, Wibowo A, Pranata R. Prognostic value of elevated lactate dehydrogenase in patients with COVID-19: a systematic review and meta-analysis. Postgrad Med J. 2021;postgradmedj-2020-139542. doi:10.1136/postgradmedj-2020-139542 


\section{Publish your work in this journal}

The Journal of Asthma and Allergy is an international, peer-reviewed open-access journal publishing original research, reports, editorials and commentaries on the following topics: Asthma; Pulmonary physiology; Asthma related clinical health; Clinical immunology and the immunological basis of disease; Pharmacological interventions and new therapies. The manuscript management system is completely online and includes a very quick and fair peer-review system, which is all easy to use. Visit http://www.dovepress.com/testimonials.php to read real quotes from published authors.

Submit your manuscript here: https://www.dovepress.com/journal-of-asthma-and-allergy-journal 